\title{
Reduction of gastric ulcer recurrence after suppression of Helicobacter pylori by cefixime
}

\author{
M Tatsuta, H Ishikawa, H Iishi, S Okuda, Y Yokota
}

\begin{abstract}
The effect on the recurrence of gastric ulcers after suppression of Helicobacter pylori by combined treatment with cimetidine and the antimicrobial drug cefixime was investigated. Twenty one of 43 patients with endoscopically proved gastric ulcer and $\boldsymbol{H}$ pylori infection were randomly assigned to receive cimetidine $800 \mathrm{mg}$ daily for 12 weeks; the remaining 22 patients received cimetidine $800 \mathrm{mg}$ daily for 12 weeks plus cefixime $100 \mathrm{mg}$ daily for the last two weeks. After treatment, $88 \%$ of 17 patients on cimetidine only remained $\boldsymbol{H}$ pylori positive, whereas combined administration of cimetidine and cefixime had suppressed $\boldsymbol{H}$ pylori in $78 \%$ of 18 patients $(p<0.05)$. Seventeen patients in the former group whose ulcers healed but who remained $\boldsymbol{H}$ pylori positive and 18 patients in the latter group whose ulcers healed and who were no longer infected with $H$ pylori continued to be followed after treatment. These patients underwent endoscopy to detect ulcer recurrence if symptomatic, or at 12 and 24 weeks if asymptomatic. At 12 weeks, recurrence was observed in seven of $15(47 \%)$ patients in whom $H$ pylori persisted, but in only one of $14(7 \%)$ patients in whom $H$ pylori had been suppressed $(p<0.05)$. At 24 weeks, however, recurrence rates were similar between the two groups. These findings indicate that $H$ pylori infection may be closely related to early ulcer recurrence.
\end{abstract}

A strong correlation between the presence of Helicobacter pylori and histological evidence of gastritis and peptic ulcer has been well documented. ${ }^{1-4}$ Recently, Marshall and associates found that in duodenal ulcer patients in whom $H$ pylori had not been eliminated, the ulcer crater healed in only $61 \%$ and ulcers recurred in $84 \%$ during a one year follow up period. These authors also found that $H$ pylori suppression was associated with healing of the ulcer in $92 \%$ of patients, with ulcer recurrence in only $21 \%$. On the basis of these findings, they suggested that the organism may play an active role in the pathogenesis of duodenal ulcers. This putative role of $H$ pylori, however, remains unclear. ${ }^{6}$ To date, only a few preliminary studies have been conducted to evaluate the effect of antimicrobial treatment on the healing and recurrence of $H$ pylori associated gastric ulcers. ${ }^{78}$ In the present work, therefore, we tested the hypothesis that persistence of $H$ pylori after gastric ulcer healing is related to ulcer recurrence.

Patients, materials, and methods

The effect on gastric ulcer recurrence of suppres- sion of $H$ pylori by cefixime treatment was investigated. Forty three patients with endoscopically verified gastric ulcer and $H$ pylori infection entered this trial. Informed consent was obtained from each patient, and the study was carried out in accordance with the Declaration of Helsinki. Endoscopic examination was performed less than 10 days before the start of treatment. All endoscopies were performed by the same experienced endoscopists, using a side viewing gastrofibrescope (Olympus GF-10). All patients were treated on an outpatient basis.

By random allocation, 21 patients were assigned to receive oral treatment with cimetidine only ( $200 \mathrm{mg}$ three times daily after meals and at bedtime) for 12 weeks. The remaining 22 patients received cimetidine at the same dosage for 12 weeks, plus cefixime (Gefspan; Fujisawa Pharmaceutical Co Ltd, Osaka, Japan) (50 mg orally twice daily after breakfast and dinner) for two weeks from weeks 10 to 12 . All patients kept a daily record of their drug consumption and were followed at the hospital every two weeks. Endoscopy was repeated 12 weeks after the start of treatment by the same endoscopist, who had no knowledge of the patient's treatment or clinical progress. Healing was defined as the resolution of an ulcer crater. Patients whose ulcers had not healed at 12 weeks were withdrawn from further study. The remaining patients received neither further medication nor antacids, but were followed at the hospital every four weeks to check for symptom recurrence. Endoscopy was again repeated at the time of symptom recurrence, or at 12 and 24 weeks in those who remained asymptomatic. Endoscopy was performed by the same endoscopist, who remained unaware of the patient's earlier treatment. The reappearance of an ulcer crater was considered to represent recurrence whether or not symptoms were present.

At each endoscopic examination, two biopsy specimens were taken from an area of intact mucosa at a distance of $1 \mathrm{~cm}$ from an ulcer crater or a healed ulcer, using a sterilised biopsy forceps (Olympus FB-25K). Endoscopes were cleaned with a detergent, disinfected with $70 \%$ ethanol, and rinsed with sterile water after each examination.

One biopsy specimen was fixed in $20 \%$ formalin for histological examination. Another specimen was homogenised in a microhomogeniser (Radnoti, Glass, California) with about $100 \mu \mathrm{l}$ of sterile saline. The specimen was inoculated over the surface of Brucella agar (BBL) plate with $7 \%$ defibrinated horse blood added Campylobacter selective supplement (Skirrow, Oxoid). The procedure was performed within two to three hours after sampling. All 
agars were incubated at $37^{\circ} \mathrm{C}$ for four days under $10 \% \mathrm{CO}_{2}$ incubation.

The specimen was considered positive for $H$ pylori if one or more colonies of Gram negative, oxidase positive, catalase positive, and urease positive spiral or curved rods were present. Then the one colony was cultured and identified by other physiological characteristics; no hydrolysis of hippurate, no growth in medium with $1 \%$ glycine, $1 \cdot 5 \%$ sodium chloride and $8 \%$ glucose, sensitive to cephalothin ( $30 \mu \mathrm{g} /$ disk $)$, resistant to nalidixic acid (30 $\mu \mathrm{g} /$ disk), and growth in medium with $0.04 \%$ tetrazolium chloride. The examining bacteriologist was unaware of the endoscopic findings or the treatment regimen.

After acceptance into the study, the patients were interviewed in detail, with particular reference to cigarette consumption and ingestion of aspirin or non-steroidal anti-inflammatory drugs.

The smoking index was defined as the number of cigarettes smoked per day multiplied by the duration of smoking in years. ${ }^{910}$ In calculating the duration of smoking, any pause in smoking lasting more than one year was subtracted. People with a smoking index of over 400 were defined as 'heavy smokers'. Non-smokers were defined as never having smoked.

Consumption of aspirin and non-steroidal anti-inflammatory drugs was defined as follows: nil, less than one tablet or capsule per month; mild, one to six tablets or capsules per month; moderate, two to five tablets or capsules per week; and heavy, six or more tablets or capsules per week for at least two consecutive months.

Statistical analysis was performed with the $\chi^{2}$ test or Fisher's exact probability test, or by one way analysis of variance with Dunn's multiple comparison. ${ }^{11-13}$ Data are given as mean (SE). 'Significant' indicates a calculated $p$ value of less than 0.05 .

\section{Results}

ULCER HEALING

Ulcer healing at 12 weeks was similar in both

TABLE I Effect of oral administration of cefixime on Helicobacter pylori in patients with both $\mathrm{H}$ pylori infection and gastric ulcer after treatment

\begin{tabular}{llcl}
\hline & \multicolumn{2}{l}{ H pylori infection (\%) } & \\
\cline { 2 - 3 } Treatment & Positive & Negative & Total \\
\hline Cimetidine alone & $15(88)$ & $2(12)$ & $17(100)$ \\
Cimetidine plus cefixime & $4(22)^{\star}$ & $14(78)$ & $18(100)$ \\
Total & $19(54)$ & $16(46)$ & $35(100)$ \\
\hline
\end{tabular}

* Significantly different from the value for patients treated with cimetidine alone, $\mathrm{p}<0.05$.

TABLE II Effect of suppression of Helicobacter pylori on gastric ulcer recurrence 12 weeks after treatment

\begin{tabular}{llllll}
\hline & $\begin{array}{l}\text { H pylori } \\
\text { infection } \\
\text { after }\end{array}$ & No of & & Recurrence at week 12(\%) & \\
\cline { 5 - 6 } treatment & patients & Total & Asymptomatic & Symptomatic \\
\hline Cimetidine alone & Positive & 15 & $7(47)$ & 6 & 1 \\
Cimetidine plus & Negative & 2 & $1(50)$ & 1 & 0 \\
cefixime & Positive & 4 & $2(50)$ & 2 & 0 \\
\hline
\end{tabular}

^Significantly different from the value for patients positive for $H$ pylori infection after cimetidine treatment, $\mathrm{p}<0.05$.
TABLE III Clinical data after treatment for patients with healed gastric ulcer treated with cimetidine alone or cimetidine plus cefixime

\begin{tabular}{|c|c|c|}
\hline Data & $\begin{array}{l}\text { Patients with } \\
\text { positive } \mathrm{H} \text { pylori } \\
\text { infection after } \\
\text { cimetidine }\end{array}$ & $\begin{array}{l}\text { Patients with no } \\
\text { H pylori infection } \\
\text { after cimetidine } \\
\text { plus cefixime }\end{array}$ \\
\hline No & 15 & 14 \\
\hline Men:women & $11: 4$ & $9: 5$ \\
\hline Age (yrs), mean (SE) & $57(2)$ & $58(2)$ \\
\hline \multicolumn{3}{|c|}{ Stage of healed ulcer $(\mathrm{No}(\%))$} \\
\hline Red scar stage & $14(93)$ & $14(100)$ \\
\hline White scar stage & $1(7)$ & $0(0)$ \\
\hline \multicolumn{3}{|c|}{ Location of healed ulcer } \\
\hline Upper corpus & $1(7)$ & $1(7)$ \\
\hline Middle corpus & $2(13)$ & $1(7)$ \\
\hline Lower corpus & $1(7)$ & $1(7)$ \\
\hline Angulus & $10(66)$ & $9(65)$ \\
\hline Antrum & $1(7)$ & $2(14)$ \\
\hline \multicolumn{3}{|c|}{ Smoking index (No (\%)) } \\
\hline 0 & $5(33)$ & $3(21)$ \\
\hline $1-400$ & $3(20)$ & $5(36)$ \\
\hline 401- & $7(47)$ & $6(43)$ \\
\hline \multicolumn{3}{|l|}{ Aspirin (No (\%)) } \\
\hline None & $12(80)$ & $13(93)$ \\
\hline Mild & $3(20)$ & $1(7)$ \\
\hline Moderate & $0(0)$ & $0(0)$ \\
\hline Heavy & $0(0)$ & $0(0)$ \\
\hline \multicolumn{3}{|l|}{ NSAID (No (\%)) } \\
\hline None & $12(80)$ & $14(100)$ \\
\hline Mild & $3(20)$ & $0(0)$ \\
\hline Moderate & $0(0)$ & $0(0)$ \\
\hline Heavy & $0(0)$ & $0(0)$ \\
\hline
\end{tabular}

None of the differences between the two groups were statistically significant.

NSAID $=$ Non-steroidal anti-inflammatory drugs.

treatment groups: it occurred in 17 of $20(85 \%)$ patients who received cimetidine alone, compared with 18 of $22(82 \%)$ patients who received cimetidine plus cefixime. One patient on cimetidine refused to undergo the second endoscopy. Seven patients (three on cimetidine and four on cimetidine plus cefixime) were withdrawn from further study because their ulcers had not healed.

\section{EFFECT OF TREATMENT ON H PYLORI}

Table I summarises the effect on $H$ pylori of a two week course of cefixime. Administration of cimetidine and cefixime suppressed $H$ pylori in 14 of $18(78 \%)$ patients, whereas 15 of $17(88 \%)$ patients receiving cimetidine alone remained $H$ pylori positive during follow up. The difference was statistically significant $(\mathrm{p}<0 \cdot 05)$.

\section{ULCER RECURRENCE AT 12 WEEKS}

Thirty five patients with healed gastric ulcers entered the follow up phase of the trial. All patients completed all aspects of the study until week 12 .

The results are summarised in Table II. At 12 weeks, the ulcer recurred in seven of $15(47 \%)$ patients treated with cimetidine only who remained $H$ pylori positive. In contrast, ulcer recurrence occurred in only one of 14 patients (7\%) in whom $H$ pylori was not detected after treatment with cimetidine plus cefixime $(p<0.05)$. Almost all of the recurrences were asymptomatic.

At 12 weeks, recrudescence of the infection occurred in 10 of $14(71 \%)$ patients in whom $H$ pylori had been suppressed by cimetidine and cefixime. In only one of these 10 patients did the ulcer relapse.

Table III shows that the patients in the two groups did not differ significantly in respect of 
TABLE IV Factors that may influence gastric ulcer recurrence 12 weeks after treatment

\begin{tabular}{lll}
\hline Factors & $\begin{array}{l}\text { Recurrent } \\
\text { ulcers }\end{array}$ & $\begin{array}{l}\text { Non-recurrent } \\
\text { ulcers }\end{array}$ \\
\hline No & 11 & 21 \\
Men:women & $8: 3$ & $14: 7$ \\
Age (yrs), mean (SE) & $58(3)$ & $57(4)$ \\
Stage of healed ulcer (No (\%)) & $11(100)$ & $20(95)$ \\
Red scar stage & $0(0)$ & $1(5)$ \\
White scar stage & $2(19)$ & $0(0)$ \\
Lncation of healed ulcer (No (\%)) & $3(27)$ & $1(5)$ \\
Upper corpus & $3(27)$ & $0(0)$ \\
Middle corpus & $2(19)$ & $17(81)$ \\
Lower corpus & $1(8)$ & $3(14)$ \\
Angulus & & \\
Antrum & $0(0)$ & $8(38)$ \\
Smoking index ${ }^{\star}($ No (\%)) & $2(18)$ & $7(33)$ \\
0 & $9(82)$ & $6(29)$ \\
l-400 & & \\
401- & $7(88)$ & $18(86)$ \\
Aspirin (No (\%)) & $1(12)$ & $3(14)$ \\
None & $0(0)$ & $0(0)$ \\
Mild & $0(0)$ & $0(0)$ \\
Moderate & & \\
Heavy & $6(75)$ & $20(95)$ \\
NSAID (No (\%)) & $2(25)$ & $1(5)$ \\
None & $0(0)$ & $0(0)$ \\
Mild & $0(0)$ & $0(0)$ \\
Moderate & & \\
Heavy & &
\end{tabular}

^Differences in the incidence of ulcers located in the upper, middle, and lower corpus and the incidence of heavy smokers with a smoking index of more than 400 between the patients in whom ulcer did or did not recur were statistically significant, $p<0.001$ and $\mathrm{p}<0.01$, respectively.

NSAID $=$ Non-steroidal anti-inflammatory drugs.

sex, age, location and stage of healed ulcers, proportion of cigarette smokers, and proportion of habitual aspirin and non-steroidal antiinflammatory drug users.

FACTORS INFLUENCING ULCER RECURRENCE AT 12 WEEKS

Ulcers recurred in 11 patients at or within 12 weeks, whereas 21 patients continued in remission off treatment. As shown in Table IV, recurrence was significantly more frequent in patients with ulcers located in the gastric corpus $(\mathrm{p}<0.001)$ and in heavy smokers $(\mathrm{p}<0.01)$. However, sex, stage of healed ulcer, cigarette consumption, and aspirin or non-steroidal antiinflammatory drug ingestion did not show any significant correlation with ulcer recurrence.

\section{ULCER RECURRENCE AT 24 WEEKS}

At week 24, four patients were withdrawn from the study because they refused the third endoscopy. Two of them healed on cimetidine but remained $H$ pylori positive, one healed on cimetidine plus cefixime but remained $H$ pylori positive, and one healed on combination treatment and was cleared of $H$ pylori.

At or within 24 weeks, of the 13 patients treated with cimetidine who remained $H$ pylori positive, ulcer relapse occurred in $10(77 \%)$, while ulcer recurrence was found in eight $(62 \%)$ of 13 patients in whom $H$ pylori had been suppressed by the combined treatment with cimetidine and cefixime. The difference was not statistically significant.

\section{Discussion}

Since 1983 when Marshall cultured Gram negative urease producing bacilli from the gastric antrum of patients with peptic ulcer disease, ${ }^{1+}$ considerable interest has been aroused by the possible role of $H$ pylori in this disease. Goghlan $e a \mathbf{l}^{\text {'s }}$ suggested that only $H$ pylori status after treatment was a significant predictor of duodenal ulcer. These authors found that patients who remained culture positive had a significantly greater incidence of relapse compared with culture negative patients. Marshall et $a l^{5}$ reported similar results.

Nearly $100 \%$ of patients with duodenal ulcer are $H$ pylori positive whereas approximately two thirds of patients with gastric ulcer are positive. ${ }^{616}$ Therefore, the role of $H$ pylori in the pathogenesis of gastric ulcer remains unclear. Little evidence is available, and involves similar considerations to that for duodenal ulcer. Antimicrobial treatment and bismuth subcitrate can heal gastric ulcers, ${ }^{7817}$ and patients treated with furazolidone may have a lower relapse rate. These data are, however, preliminary. In the present work, we found that early recurrence of gastric ulcer was significantly more frequent in patients who remained culture positive compared with culture negative patients.

How bacterial infection can lead to gastric ulcer recurrence is at present unclear. $H$ pylori have been shown to produce not only a urease but also a peptidase capable of digesting gastric mucin. ${ }^{18}$ It has been postulated ${ }^{19}$ that the urease activity of the organism is the factor that breaks the mucosal barrier and thereby allows the ulcerative process to begin, and that suppression of the organism may interrupt this process and reduce the rate of relapse.

The causes of gastric ulcer relapse have not been clearly established. In the present work, we examined the influence of several patient variables on recurrence rate. We found that proximal location of the ulcer and heavy smoking were closely correlated with ulcer recurrence, but no significant correlation between ulcer recurrence and other variables was found. In other studies of ulcer relapse, the importance of age, sex, and smoking have been emphasised..$^{20}$ In the present work, we found that when $H$ pylori recrudesced in 10 patients at 12 weeks, ulcer relapse occurred in one patient but not in the remaining nine patients. These findings indicate that although suppression of $H$ pylori may prevent ulcer recurrence, $H$ pylori infection is one of the factors that determines relapse.

1 Marshall BJ, Warren JR. Unidentified curved bacilli in the stomach of patients with gastritis and peptic ulcerations. Lancet 1984; i: $1131-4$.

2 Steer HW. The gastro-duodenal epithelium in peptic ulceration. F Pathol 1985; 146: 355-62.

3 Goodwin CS, Armstrong JA, Marshall BJ. Campylobacter pyloridis, gastritis, and peptic ulceration. $\mathcal{F}$ Clin Pathol 1986; 39: 353-65.

4 Jones DM, Lessels AM, Eldridge J. Campylobacter-like organism on the gastric mucosa: culture, histological and organism on the gastric mucosa: culture, histolog
serological studies. $\mathcal{F}$ Clin Pathol 1984; 37: 1002-6.

5 Marshall BJ, Goodwin CS, Warren JR, et al. Prospective double-blind trial of duodenal ulcer relapse after eradication

6 Dooley CP, Cohen H. The clinical significance of Campylobacter pylori. Ann Intern Med 1988; 108: 70-9.

7 Zheng ZT, Wang ZY, Chu YX, et al. Double-blind short-term trial of furazolidone in peptic ulcer. Lancet 1985; i: 1048-9.

$8 \mathrm{Zhao} \mathrm{HY,} \mathrm{Li} \mathrm{G}$, Guo J, et al. Furazolidone in peptic ulcer. Lancet 1985; ii: 276-7.

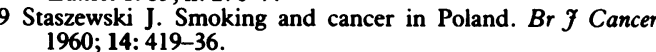

10 Staszewski J. Smoking and cancer of the alimentary tract in Poland. Brf Cancer 1969; 22: 247-53.

11 Miller RG Jr. Simultaneous statistical inference. New York: McGraw-Hill Book Co, 1966. 
12 Siegel S. Nonparametric statistics for the behavioral sciences. New York: McGraw-Hill, 1956

13 Snedecor CW, Cochran MG. Statistical methods. Ames, IA:

Iowa University Press, 1967 .
14 Marshall B. Unidentified curved bacilli on gastric epithelium in active chronic gastritis. Lancet 1983; i: 1273-5.

15 Goghlan JG, Gilligan D, Humphries H, et al. Campylobacter pylori and recurrence of duodenal ulcers - a 12-month follow-up study. Lancet 1987; i: 1109-11.

16 Itoh T, Yanagawa Y, Shingaki M, et al. Isolation of Campylobacter pyloridis from human gastric mucosa and characterization of the isolates. Microbiol Immunol 1987; 31: 603-14.
17 Brogden RN, Pinder RM, Sawyer PR, Speight TM, Avery GS. Tripotassium di-citrato bismuthate: a report of its pharmacological properties and therapeutic efficacy in peptic ulcer. Drugs 1976; 12: 401-11.

18 Slomiany B, Bilski J, Murty VLN, Sarosiek J, Dorkkin B. Campylobacter pyloridis degrades mucin and undermines Campylobacter pyloridis degrades mucin and undermines

19 Hazell SL, Lee A. Campylobacter pyloridis, urease, hydrogen ion back diffusion, and gastric ulcers. Lancet 1986; ii: 15-7.

20 Sontag S, Graham DY, Belsito A, et al. Cimetidine, cigarette

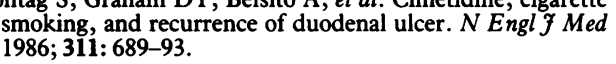

